\title{
Dev gastrik leiomyosarkom: nadir bir olgu sunumu
}

\section{Giant gastric leiomyosarcoma: a rare case report}

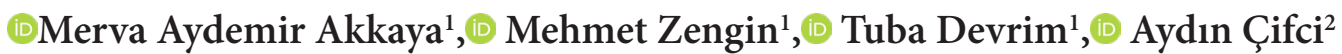 \\ ${ }^{1}$ Kırıkkale Üniversitesi Tıp Fakültesi, Tıbbi Patoloji Anabilim Dalı, Kırıkkale, Türkiye \\ ${ }^{2}$ Kırıkkale Üniversitesi Tıp Fakültesi, İç Hastalıkları Anabilim Dalı, Kırıkkale, Türkiye
}

Cite this article as/Bu makaleye atıf için: Aydemir Akkaya M, Zengin M, Devrim T, Çifci A. Dev gastrik leiomyosarkom: nadir bir olgu sunumu. J Med Palliat Care 2020; 1(4): 116-119.

\begin{abstract}
ÖZ
Leiomyosarkom en sık retroperitonda görülen düz kas orijinli nadir bir tümördür. Genelde 5. dekattan sonra kadın ve erkeklerde eşit oranda görülür. Visseral organlar arasında en sık uterusta izlenmekte olup, mide malign tümörlerinin \%1'ini oluşturur. Burada mide yerleşimli dev bir leiomyosarkom olgusu literatür eşliğinde tartışıldı. 74 yaşında kadın hasta, gastrik tümöral lezyon nedeniyle genel cerrahi kliniğinde wedge rezeksiyon uygulandı. Materyalinin makroskopik incelemesinde 14x10x8,5 cm ölçülerinde yumuşak kıvamlı nodüler bir lezyon saptandı. Lezyon submukozal yerleşimli olup muskularis propriaya da uzanım göstermekte idi. Lezyonun histopatolojik incelemesinde eozinofilik sitoplazmaya sahip iğsi hücrelerin sellüler bir proliferasyonu görüldü. Bu hücrelerde mitoz, pleomorfizm ve nekroz izlendi. Yapılan immünhistokimyasal çalışmada SMA, desmin ve vimentin ile pozitif boyanma DOG-1 ve CD117 ile de negatif boyanma saptandı. Bu bulgular eşliğinde olguya leiomyosarkom tanısı verildi. Mide yerleşimli leiomyosarkomlar oldukça nadir görülmekle beraber submukozal tümöral lezyonların, özellikle de gastrointestinal stromal tümör (GISST)’ün , ayırıcı tanısında mutlaka akılda tutulmalıdır. Bu tümörlerin GİST’ten ayırımında immünhistokimyasal çalışma oldukça yararlıdır.
\end{abstract}

Anahtar Kelimeler: Leiomyosarkom, mide, düz kas orijinli tümör

\begin{abstract}
Leiomyosarcoma is a rare tumor of smooth muscle origin, most commonly seen in retroperitoneum. It is usually seen after the $5^{\text {th }}$ decade equally among women and men. Among the visceral organs, it is most commonly seen in the uterus and constitutes $1 \%$ of malignant tumors of the stomach. Here, a case of giant leiomyosarcoma located in the stomach was discussed in the light of the literature. A 74-year-old female patient underwent wedge resection in the general surgery clinic for gastric tumor. Macroscopic examination of the material revealed a soft nodular lesion measuring $14 \times 10 \times 8.5 \mathrm{~cm}$. The lesion was submucosal and extended to the muscularis propria. Histopathological examination of the lesion revealed a cellular proliferation of spindle cells with eosinophilic cytoplasm. Mitosis, pleomorphism and necrosis were observed in these cells. Immünohistochemical study revealed positive staining with SMA, desmin and vimentin, negative staining with DOG-1, CD117. Thus, the patient was diagnosed as leiomyosarcoma. Although gastric leiomyosarcoma is very rare, it should be kept in mind in the differential diagnosis of submucosal tumoral lesions, especially gastrointestinal stromal tumor (GIST). In these tumors, immünohistochemical study is very useful in differentiation from GIST.
\end{abstract}

Keywords: Leiomyosarcoma, stomach, tumor of smooth muscle origin

\section{GİRIS}

Leiomyosarkom düz kas orijinli, en çok retroperitonu tutan ve visseral organlarda nadiren görülen bir tümördür (1). Organ tutulumu en çok uterus ve midede görülür. Mide malign lezyonlarının \%1'ini oluşturmakta olup, gastrointestinal sistemin en sı mezenkimal tümörü olan gastrointestinal stromal tümör (GİST)'ün ayırıcı tanısında düşünülmesi gereken önemli bir antitedir $(1,2)$. Sıklıkla abdominal ağrı, dispepsi, hematemez ve melena gibi

semptomlarla kendini göstermekle beraber tümör yerleşim yeri ve boyutuna göre kliniği oldukça değişmektedir (3). Mikroskopik incelemede eozinofilik sitoplazmalı, mitotik indeksi artmış iğsi hücrelerin prolifeasyonundan oluşan bir görünüm izlenmektedir. İmmünhistokimyasal olarak SMA ve desmin gibi düz kas belirteçleri ile pozitif boyanma gösterir $(3,4)$. Leiomyosarkomun prognozunda en önemli faktörler tümörün derecesidir. Bu belirlenirken 
tümörün diferansiasyonu, nekroz ve mitoz göz önünde bulundurulmaktadır. Submukozaya sinırlı lezyonlarda endoskopik cerrahi yapılabilirken, daha büyük lezyonlarda wedge rezeksiyon veya subtotal rezeksiyon tercih edilmektedir (4). Bu yazıda dev bir gastrik leiomyosarkom olgusu sunuyoruz.

\section{OLGU}

Çalışmamız sırasında gerçekleştirilen tüm prosedürlerin 1964 Helsinki Bildirgesi ve ulusal/kurumsal etik standartlara ile uyumlu olmasına dikkat edildi. Hastadan bilgilendirilmiş onam alındı. Yazarların çıkar çatışması mevcut değildir ve herhangi bir finansal katılımı yoktur.

Yetmiş dört yaşında kadın hasta hızlı kilo kaybı ve denge bozukluğu şikayeti ile genel cerrahi kliniğine başvurdu. Anamnezinde, fizik muayenede ve laboratuvar testlerinde herhangi bir özellik saptanmadı. Batın bilgisayarlı tomografisinde mide büyük kurvatür hizasında, antruma bası yapan $14 \mathrm{~cm}$ çapında submukozal bir lezyon tesbit edildi. Eksploratif laparotomide bu kitle wedge rezeksiyon ile eksize edilip bölümümüze gönderildi.
Makroskobik incelemede, üzerinde $12 \times 4 \mathrm{~cm}$ ölçüsünde mukoza bulunan $14 \times 10,5 \times 8,5 \mathrm{~cm}$ ölçülerindeki rezeksiyon materyalinin kesitlerinde mukoza altında, kasa infiltre 14x10x8,5 cm ölçülerinde, kirli sarı renkli, elastik kıvaml,, solid, nodüler bir lezyon izlendi. Mikroskopik incelemede submukozada lokalize, muskularis propria da uzanım gösteren ekspansif sınırlı tümöral bir lezyon görüldü. Tümör fasiküller ve demetler oluşturan, iğsi nukleuslu, eozinofilik sitoplazmalı, kaba kromatin dağılımına sahip hücrelerden oluşmaktaydı (Şekil 1a, 1b, 1c). Bu hücrelerde orta derecede nükleer atipi ve nükleer pleomorfizm izlendi. Kesitlerde yer yer sellülaritede artış ve nekroz mevcuttu. Mitoz 2-3/10 BBA olarak saptandı. Yapılan immünhistokimyasal incelemede tümöral hücrelerde vimentin (+), SMA (+) (Şekil 1d), desmin zayıf (+), kaldesmon (-), MSA (-), sitokeratin (-), CD117 (-) (Şekil 1e), DOG-1 (-), CD31 (-), CD34 (-), S-100 (-), kromogranin (-), sinaptofizin (-), CD56(-) olarak saptandı. Ki-67 indeksi yaklaşı \%5 olarak değerlendirildi (Şekil 1f). Morfolojik ve immünohistokimyasal bulgular eşliğinde olgu "Leiomyosarkom, Grade 2" olarak rapor edildi.
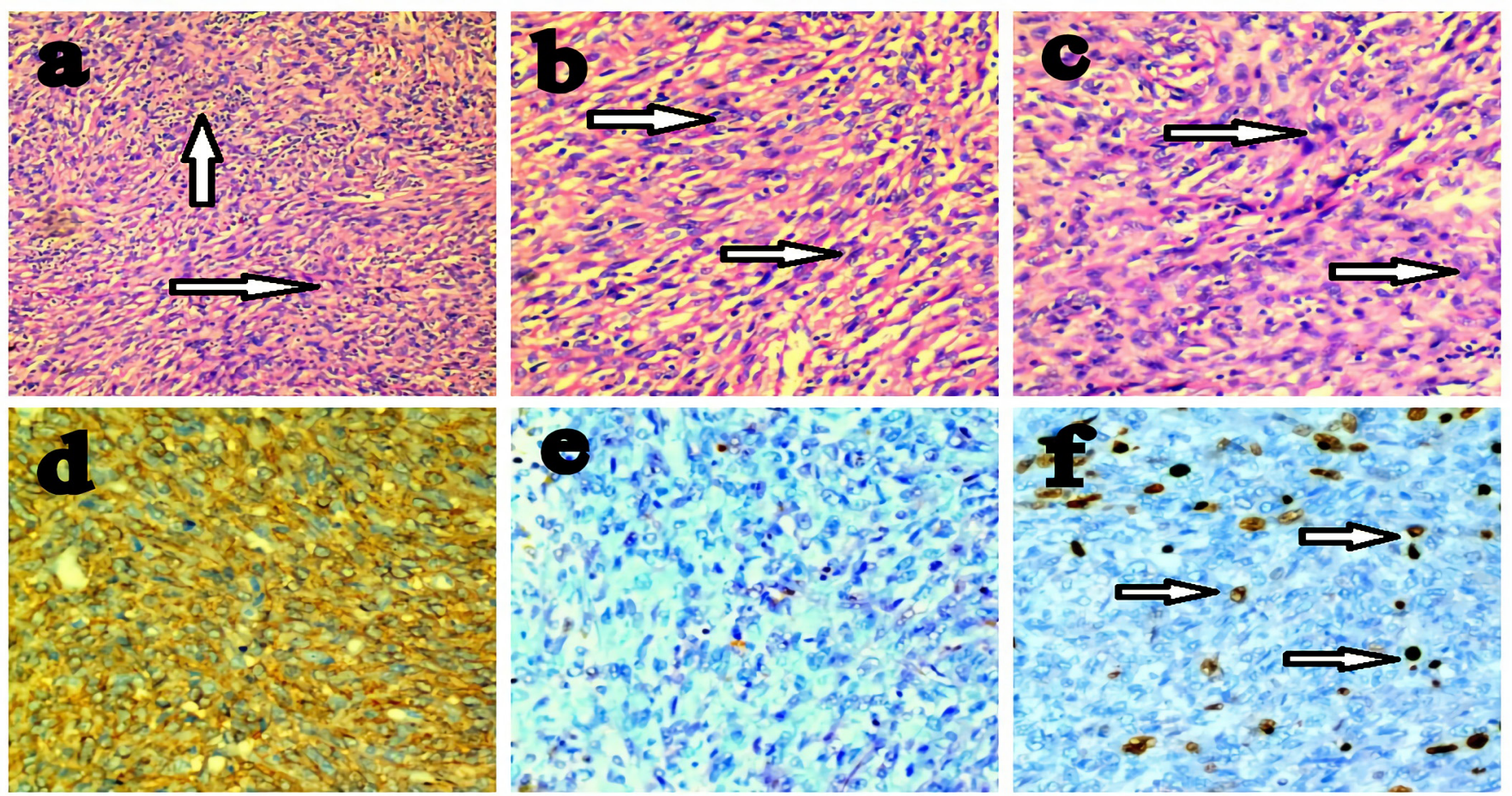

Şekil. Leiomyosarkomun histopatolojik görünümü. (a, b, c) Tümör yer yer demetler oluşturan, eozinofilik sitoplazmalı, kaba kromatin dağılımına sahip iğsi nukleuslu hücrelerden olusmaktaydı (oklar). (d) Tümöral hücrelerde düz kas aktin (SMA) pozitif olarak izlendi. (e) Tümöral hücrelerde CD117 (-) negatif olarak izlendi. (f) Tümörde Ki-67 indeksi yaklaşık \%5 olarak görüldü (oklar).

\section{TARTIŞMA}

Leiomyosarkom düz kas orijinli, en çok retroperitonda görülen nadir tümörlerdendir. Bu lokalizasyon dışında ekstremitelerde, daha nadiren de uterus ve midede görülür (1). Mide yerleşimli leiomyosarkom genelde 5.dekaddan sonra, kadın ve erkeklerde eşit oranlarda görülür. Yamamoto ve arkadaşlarının yaptığı bir çalışmada gastrointestinal yerleşimli 55 leiomyosarkom olgusunun sadece 4 tanesinin mide yerleşimli olduğu görülmüştür (1). Literatürde de 2000'lerin başından beri sadece 13 olgunun gastrik leiomyosarkom tanisı 
aldığını görmekteyiz. Ayrıca c-kit immünhistokimyası bulunmadan önce birçok GIST olgusunun leiomyom ya da leiomyosarkom tanısı aldığını gösteren çalışmaların da olması aslında gastrik leiomyosarkom olgularının ne kadar nadir olduğunu göstermektedir $(2,3)$.

Tümör çoğunlukla büyük kurvatur (\%25) ve fundus (\%20) yerleşimlidir (4). Gastrik leiomyosarkom olguları küçük boyutlardayken asemptomatik seyredebilirken, büyüdükçe tutulum yerine göre abdominal ağr1, epigastrik hassasiyet, gastrointestinal kanama, kilo kaybı gibi semptomlarla kendini gösterir. Ayrıca gastrik mukozada ülserle prezente olan bu tümörler uzun süre gastrik ülser tedavisiyle takip edilebilmektedir $(4,5)$. Olgumuzda tümör büyük kurvatürde yerleşmiş olup uzun süre asemptomatik seyretmiştir

Leiomyosarkom tanısı cerrahi olarak çıkarılan lezyonun patolojik incelemesiyle verilir. Muskularis propriadan gelişen tümörün mikroskopik incelemesinde eozinofilik sitoplazmaya sahip, iğsi nükleuslu hücelerin sellüler proliferasyonu izlenir. Bu hücrelerde değişken derecelerde atipi, hiperkromazi ve pleomorfizm saptanır (6). Artmış mitotik indeks ve nekroz sıklıkla mevcuttur. İmmünhistokimyasal olarak düz kas markırları olan SMA ve desmin pozitivitesi ile kesin tanı verilir. Ayırıc1 tanıya diğer stromal tümörler, en önemlisi de GÍST girer (6,7). Gastrointestinal sistemde en sik görülen mezenkimal orijinli tümör olan GİST, leiomyosarkomla da yer yer histopatolojik benzerlik gösterebilir. Ancak, GİST'te izlenen CD117 ve DOG-1 pozitivitesi bu iki antiteyi ayırmak açısından önemlidir (7). Olgumuzun morfolojik özellikleri literatür ile uyumludur.

Leiomyosarkomların malignite potansiyelinin değerlendirilmesinde tümörün diferasiyasyonu, mitoz ve nekroz değerlendirilerek skorlanır ve toplam skora göre de tümörün grade'i belirlenir (8). Toplam skor 2-3 ise grade 1, 4-5 ise grade 2, >6 ise grade 3 olarak değerlendirilir. TNM evrelemesine göre yapılan bu grade'leme (Tablo), hasta prognozu ve buna yönelik tedavi planının belirlemesi açısından oldukça önemlidir. Leiomyosarkomlarda tümör boyutu da önemli bir prognostikfaktördür. Opere edilmişvakalarda kötü hasta sağkalımı tümör boyutunun büyük olması ile pozitif korelasyon göstermektedir $(8,9)$. Ayrıca tümör boyutu 10 cm'yi geçtiğinde karaciğer ve peritoneal metastaz riskinin arttığı bildirilmektedir. Leiomyosarkomlarda diğer önemli bir prognostik faktör de cerrahi sinırdır. Literatürde rekürrens oranları ve metastazın, cerrahi sınır pozitifliği olan hastalarda arttığı bildirilmektedir (9). Boyutu $10 \mathrm{~cm}$ 'yi aşan olgumuzda mitozun ve nekrozun arttığı, diferansiasyonun da yer yer düştüğü alanlar izlendiği için tümör grade 2 ile uyumlu olarak değerlendirilmiştir.

\begin{tabular}{|c|c|c|}
\hline $\begin{array}{c}\text { Tümör } \\
\text { diferansiyasyonu }\end{array}$ & Mitoz Sayısı & Nekroz \\
\hline İyi = Skor 1 & 1/10 BBA -> Skor 1 & Nekroz yok = Skor 1 \\
\hline Orta $=$ Skor 2 & 1-5/10 BBA ->Skor 2 & $\begin{array}{l}\text { Tümörün \%50'sinden } \\
\text { azında mevcut = Skor } 2\end{array}$ \\
\hline Kötü = Skor 3 & $>10 / 10$ BBA -> Skor 3 & $\begin{array}{c}\text { Tümörün \%50'sinden } \\
\text { fazlasında mevcut = Skor } 3\end{array}$ \\
\hline
\end{tabular}

Gastrik leiomyosarkom tedavisinde parsiyel gastrektomi önerilmektedir. Yapılan çalışmalarda distal subtotal gastrektomi yapılan hastaların proksimal ya da wedge rezeksiyon uygulananlara göre daha yüksek sağkalıma sahip oldukları görülmüştür (10). Parsiyel gastrektomi uygulanan olgumuzun 24 aylık takibinde nüks ya da metastaz saptanmamıştır.

\section{SONUÇ}

Gastrik leiomyosarkom nadir görülmekle beraber mide yerleşimli stromal lezyonların ayırıcı tanısında akılda tutulmalıdır ve başta GIST olmak üzere birçok mezenkimal neoplazinin bu tümöre histopatolojik olarak benzemesi nedeniyle tanı tuzaklarından korunmak için immünhistokimyasal çalışmaya mutlaka başvurulmalıdır.

\section{ETIKK BEYANLAR}

Aydınlatılmış Onam: Bu çalışmaya katılan hasta(lar) dan yazılı onam alınmıştır.

Hakem Değerlendirme Süreci: Harici çift kör hakem değerlendirmesi.

Çıkar Çatışması Durumu: Yazarlar bu çalışmada herhangi bir çıkara dayalı ilişki olmadığını beyan etmişlerdir.

Finansal Destek: Yazarlar bu çalışmada finansal destek almadıklarını beyan etmişlerdir.

Yazar Katkıları: Yazarların tümü; makalenin tasarımına, yürütülmesine, analizine katıldığını ve son sürümünü onayladıklarını beyan etmişlerdir.

\section{KAYNAKLAR}

1. Yamamoto H, Handa M, Tobo T, et al. Clinicopathological features of primary leiomyosarcoma of the gastrointestinal tract following recognition of gastrointestinal stromal tumors. Histopathology 2013; 63: 194-207

2. Sato T, Akahoshi K, Tomoeda N, et al. Leiomyosarcoma of the stomach treated by endoscopic submucosal dissection. Clin J Gastroenterol 2018; 11: 291-6.

3. Insabato L, Di Vizio D, Ciancia G, et al. Malignant gastrointestinal leiomyosarcoma and gastrointestinal stromal tumor with prominent osteoclast-like giant cells. Arch Pathol Lab Med 2004; 128: 440-3.

4. Kang WZ, Xue LY, Tian YT, et al. Leiomyosarcoma of the stomach: A case report. World J Clin Cases 2019; 7: 3575-82. 
5. Farrugia G, Kim CH, Grant CS, et al. Leiomyosarcoma of the stomach: determinants of long-term survival. Mayo Clin Proc 1992; 67: 533-6.

6. Garg RM, Alrajjal AM, Berri RM, et al. Primary gastric leiomyosarcoma: a rare entity. Am J Gastroenterol 2017; 112: 1387-8.

7. Hasnaoui A, Jouini R, Haddad D, et al. Gastric leiomyosarcoma and diagnostic pitfalls: a case report. BMC Surgery 2018; 18: 62.

8. Hilal L, Barada K, Mukherji D, et al. Gastrointestinal (GI) leiomyosarcoma (LMS) case series and review on diagnosis, management, and prognosis. Med Oncol 2016; 33: 20.

9. Miettinen M, Monihan JM, Sarlomo-Rikala $M$, et al. Gastrointestinal stromal tumors/smooth muscle tumors (GISTs) primary in the omentum and mesentery: clinicopathologic and immünohistochemical study of 26 cases. Am J Surg Pathol 1999; 23: 1109-18.

10. Miettinen M, Sarlomo-Rikala M, Lasota J. Gastrointestinal stromal tumors: recent advances in understanding of their biology. Hum Pathol 1999; 30: 1213-20. 